\title{
Placental malarial parasitaemia and pregnancy outcome among parturients in a tertiary hospital in South- South Nigeria
}

\author{
Godwin J Ibanga', Aniekan M Abasiattai', Emem A Bassey', Micheal Ukpe', Olujimi A Olatunbosun', \\ Udeme Ekrikpo²
}

${ }^{1}$ Department of Obstetrics/Gynaecology, University of Uyo Teaching hospital, Uyo, Nigeria, ${ }^{2}$ Department of Internal Medicine, University of Uyo Teaching Hospital, Nigeria.

Background: Malaria is the most common human parasitic disease and continues to be a complex and overwhelming global health problem, especially in sub-Saharan Africa. Placental malaria, one of the major features of malaria in pregnancy has been associated with serious adverse health consequences to both the mother and her fetus.Objective: This study sought to determine the prevalence of maternal, cord, and placental malarial parasitaemia at parturition, the association between maternal and placental parasitaemia, and also the association between placental parasitaemia and pregnancy outcomes. Materials and Methods: A descriptive cross-sectional design was used to study 330 pregnant women selected by the systematic random sampling technique as they presented in the labour ward of University of Uyo Teaching Hospital, Uyo between April, 2012 and September, 2012. Pre-delivery, maternal peripheral blood was taken for malaria parasite (MP) and packed cell volume (PCV). Post delivery, cord blood was taken for MP and PCV estimation while placental blood was examined for MP. Neonatal demographic and clinical characteristics were also obtained. The data was analyzed using SPSS version 17. Level of statistical significance was set at $P$ less than $0.05(P<0.05)$. Results: The mean age of the respondents was $28.8 \pm 4.4$ years. The prevalence of maternal, cord, and placental parasitaemia were $30.3 \%, 14.8 \%$ and $18.2 \%$ respectively. There was a strong correlation between maternal parasitaemia and placental parasitaemia (rho $=0.75, \mathrm{P}<0.001$ ). Also, a significant linear association between cord parasitaemia and placental malaria (rho $=0.87$, $\mathrm{p}<0.001$ ) was found. Placental malaria predisposed to low birth weight (OR $1.01\{95 \% \mathrm{Cl}$ $1.001-1.02\}, p=0.04$ ) and fetal anaemia (OR $1.02\{95 \% \mathrm{Cl} 1.01-1.03\}, \mathrm{p}<0.001$. Conclusion: There is a relatively high prevalence of placental parasitaemia at parturition. Placental malaria is associated with adverse pregnancy outcomes such as low birth weight, fetal anaemia and cord parasitaemia. Proven strategies to prevent malaria in pregnancy such as use of ITNs and IPT and free antenatal care should be intensified to curb this deadly but preventable disease.

Key words: Placental malarial parasitaemia, pregnancy outcome, Uyo DOI: 10.3126/ajms.v6i6.12401

\section{INTRODUCTION}

Malaria is known to be a complex and overwhelming health problem, with 300-500 million infections and 2 to 3 million deaths occurring each year. ${ }^{1-3}$ About $90 \%$ of these deaths occur in sub-Saharan Africa. ${ }^{1}$ Each year, about 25 to 30 million pregnant women living in malaria endemic areas of Africa are affected; with about 10,000 maternal mortalities and 200,000 new born deaths. ${ }^{4-5}$
Although often asymptomatic, especially in immune women, malaria has been implicated in several studies as a cause of some unfavourable pregnancy outcomes. ${ }^{6-9}$ These outcomes include anemia in pregnancy, fetal anemia, miscarriage, intra-uterine fetal death, premature labour and congenital malaria. The adverse consequences are mainly as a result of sequestration of parasitized erythrocytes present in the placental intervillous spaces, to chondroitin sulphate A (CSA) in the placenta. ${ }^{10-12}$ 
This sequestration in the placenta is a virulence factor exclusively displayed by Plasmodium falciparum and not by other human malaria parasites. ${ }^{13}$

The World Health Organization (WHO) has recommended a three prong approach to the prevention and control of malaria during pregnancy in areas of stable transmission through the use of intermittent preventive (IPT) of asymptomatic pregnant women, use of insecticide treated nets (ITNs) and prompt and effective case management of acute malaria in pregnancy. ${ }^{14}$

Although there have been some studies demonstrating how placental parasitaemia adversely affect pregnancy outcome in some parts of the country, ${ }^{6,8,9,15}$ none has been conducted in Akwa Ibom State, South - South Nigeria. Considering the endemic nature of the disease in the State and the impact it could have on both mother and the fetus, this study was necessary to determine the prevalence of placental malaria and its influence on pregnancy outcome especially during the peri-partum period when preventive measures would have already been instituted. The findings of this study will assess the effects of the interventions in place and recommend strategies to tackle the problems of malaria in pregnancy not only in our environment, but in the country as a whole.

\section{MATERIALS AND METHODS}

Study Area: The study was carried out at the labour ward of the University of Uyo Teaching Hospital (UUTH), located in Uyo, the capital city of oil rich Akwa Ibom State, in the South-South geopolitical zone of Nigeria. Uyo is a malaria holo-endemic area located in the rain forest belt of Nigeria with a population of 3,902,051 people, of which 1,040,093 women are within the reproductive age group (2006 National Census figures). University of Uyo Teaching Hospital is the only tertiary health facility in the State and serves as a major referral centre for both government owned and privately owned maternity centers in Uyo and its environs. Antenatal clinics usually hold on Mondays, Tuesdays, Thursdays and Fridays while booking clinics hold Wednesday of every week. Apart from routine screening for hypertension, proteinuria and glycosuria, blood is usually taken for packed cell volume, (PCV), blood grouping, Rhesus typing and haemoglobin genotype. Voluntary counseling and testing for human immunodeficiency infection (HIV) is also usually carried out routinely. Also, attention is usually routinely paid to the prevention of anaemia and malaria using haematinics and intermittent preventive treatment (IPT) for malaria respectively.

Study population, recruitment and data collection A systematic random sampling technique where every second parturient who booked for antenatal care in
UUTH and presented in the labour ward for delivery, was used to recruit 330 consenting parturients into the study. Paturients who had obstetric or medical complications such as diabetes mellitus, hypertensive disorders of pregnancy, history of antepartum haemorrhage, sickle cell disease in pregnancy, and multiple pregnancy were excluded from the study. Information was obtained from respondents using an interviewer administered questionnaire.

Three $(3 \mathrm{ml})$ of blood was collected from the peripheral vein of each parturient into sample bottle containing Ethylene Diamine Tetra-Acetic Acid (EDTA), for a thick and thin film and also for estimation of PCV using standard laboratory procedures at the microbiology and side laboratories of the hospital. Test was carried out by certified medical laboratory scientists.

On completion of the third stage of labour and within 30 minutes following the expulsion of the placenta, $3 \mathrm{mls}$ of blood was collected from umbilical cord and emptied into EDTA bottle for thick blood film for MP and PCV. Two millilitres of blood was also collected from the paramedian maternal surface of the placenta with a syringe, using aspiration method, ${ }^{16}$ and emptied into an EDTA bottle for thick and thin blood films. The slides were labeled M, C, and $\mathrm{P}$ to represent maternal, cord and placental samples respectively for each subject before being transported to the microbiology laboratory for further processing and subsequent reading. A blood film was considered positive for malaria if malaria parasites were observed.

After delivery, the neonate's demographic and clinical characteristics were obtained and recorded on the questionnaire. Such data included: Gestational age at delivery, Apgar score at 5 minutes, and the birth weight of the baby in kilograms.

\section{Packed cell volume estimation}

Two non-heparinized capillary tubes for each subject, each with three-quarter of the tubes filled with blood taken from the $3 \mathrm{ml}$ of peripheral blood already obtained by venepuncture, were sealed at the distal end with plasticin. A similar procedure was done for the cord blood samples already taken. Four capillary tubes containing blood samples were then sent to the laboratory where they were placed in a centrifuge and spun at 3000 revolutions per minute for 5 minutes to determine the PCV. The PCV was read with a Hawsley's Haematocrit Reader. The mean of two values of the packed cell volume for each subject was used.

Thick and thin blood films preparation and staining A drop of blood from the maternal peripheral vein, the umbilical vein, and from the intervillous space of placenta 
respectively, was each placed on the middle portion of a clean, grease-free $76 \mathrm{~mm} \times 25 \mathrm{~mm}$ microscope glass slide, with a thick and thin film prepared separately. The drop of blood on each of the slides was then dispersed to fill a large circle at the middle of the slide to make a thick blood film. The thin film was prepared in such a way that newsprint could be read through it. The various smears were then allowed to air dry. The thin blood smear was fixed in absolute methanol for about 5 seconds and thereafter, it was removed and placed vertically on the rack for 2-3 minutes. The dry slides of both thick and thin films were stained in a trough containing 3\% Giemsa stain for 30 minutes. The slides were then removed with the aid of forceps and rinsed in buffer solution to maintain a $\mathrm{pH}$ of 7.2. The back of the slides was wiped dry and clean with the aid of dry cotton wool.

\section{Reading of slides and parasite count}

The slides were allowed to dry in atmospheric air before subjecting them to microscopic examination. The stained smears were examined under x 100 oil immersion lens of a binocular light microscope. Diagnosis of malaria was based on identification of any malaria parasite on the thick film while thin smears were used for species identification. Where malaria parasites were present, parasite density was estimated from the thick blood film by multiplying the average number of parasites per high power field (HPF) by a factor of 500 as proposed by Greenwood and Armstrong. ${ }^{17}$

For this study, low birth weight was defined as birth weight less than $2.5 \mathrm{~kg}$ irrespective of the gestational age. Babies delivered between 37 completed weeks and 42 weeks of gestation were regarded as term babies while delivery before 37 completed weeks of gestation was regarded as preterm. A PCV of less than or equal to $33 \%$ was considered as anemia for parturients while a value of less than $38 \%$ was regarded as fetal anemia.

\section{Sample size determination}

The sample size was obtained using the formula, $\mathrm{n}=\mathrm{z}^{2} \mathrm{pq} / \mathrm{d}^{2}$, where $\mathrm{n}=$ minimum sample size, $\mathrm{z}=$ a value of standard normal deviation corresponding to 1.96 , $\mathrm{p}=$ prevalence, $\mathrm{q}=1-\mathrm{p}$, and $\mathrm{d}=$ sampling error of $5 \%$. The estimated sample size was calculated to be 297 using a previously reported prevalence of placental parasitaemia of $26.2 \%{ }^{15}$ To allow for attrition rate of $10 \%$, the minimum sample size required for this study was 327 . However, 330 parturients were recruited.

\section{Statistical analysis}

Data obtained was analyzed with the statistical package for social sciences (SPSS) version 17 Inc. Chicago, Ilinois, USA and presented in tables and charts. The student t-test was employed to determine statistical difference between continuous variables while the chi-square test was used to compare proportions for categorical variables. Logistic regression was used to analyze factors associated with the main outcome variables. The level of statistical significance was taken as $\mathrm{P} \leq 0.05$.

\section{Ethical approval}

Ethical approval to carry out the study was obtained from the Ethical Review Committee of the University of Uyo Teaching Hospital, Uyo. Informed consent was obtained from parturients. Participation was voluntary.

\section{RESULTS}

A total of 330 women participated in the study with a $100 \%$ response rate. The mean age of the respondents was $28.8 \pm 4.4$ years with a range of $17-42$ years. The majority of respondents $(63.3 \%)$ had tertiary education. A higher proportion were skilled workers $(37.3 \%)$ and almost all $(99.4 \%)$ were married (Table1).

The majority $(96 \%)$ had term pregnancy with a mean gestational age of the subjects at time of delivery of $39.3 \pm 1.5$ weeks. Most $(34.9 \%)$ were nulliparous, $7 \%$ were HIV positive and the prevalence of maternal malaria parasitaemia, cord parasitaemia and placental parasitaemia were $30.3 \%, 14.8 \%$ and $18.2 \%$ respectively. The mean packed cell volume was $34.0 \pm 3 \%$ with majority $(73 \%)$ having a PCV of $>33 \%$. Seventeen $(5.2 \%)$ of the neonates had low birth weight and almost all $(96.7 \%)$ had an APGAR score of 7 or more at 5 minutes (Table 2).

Malaria preventive measures used were ITNs $(70.9 \%)$, insecticides $(78.8 \%)$, (sulphad oxine/pyrimethamine - intermittent preventive treatment

\begin{tabular}{lcc}
\multicolumn{3}{l}{ Table 1: Maternal biosocial characteristics } \\
\hline Factor & Frequency & Percentage \\
\hline Age in years & 3 & \\
$\leq 19$ & 181 & 0.9 \\
$20-29$ & 144 & 54.9 \\
$30-39$ & 2 & 43.6 \\
$40-49$ & 13 & 0.6 \\
Educational status & 108 & \\
Primary & 209 & 4.0 \\
Secondary & & 32.7 \\
Tertiary & 71 & 63.3 \\
Occupation & 73 & 21.5 \\
House wives & 37 & 22.1 \\
Traders & 26 & 11.2 \\
Students & 123 & 7.9 \\
Unskilled workers & & 37.3 \\
Skilled workers & 328 & \\
Marital status & 2 & 99.4 \\
Married & & 0.6 \\
Single & & \\
\hline
\end{tabular}


for malaria (SP-IPT) $>2$ doses $(34.2 \%)$ and both ITNs and $\geq 2$ doses of SP $(20.6 \%)$ (Table 3 ).

The proportion of women that used ITN and also took at least two doses of IPT was found to be similar among the 3 parity groups (Figure 1).

There was a significant positive linear association between placental parasitaemia and maternal parasitaemia

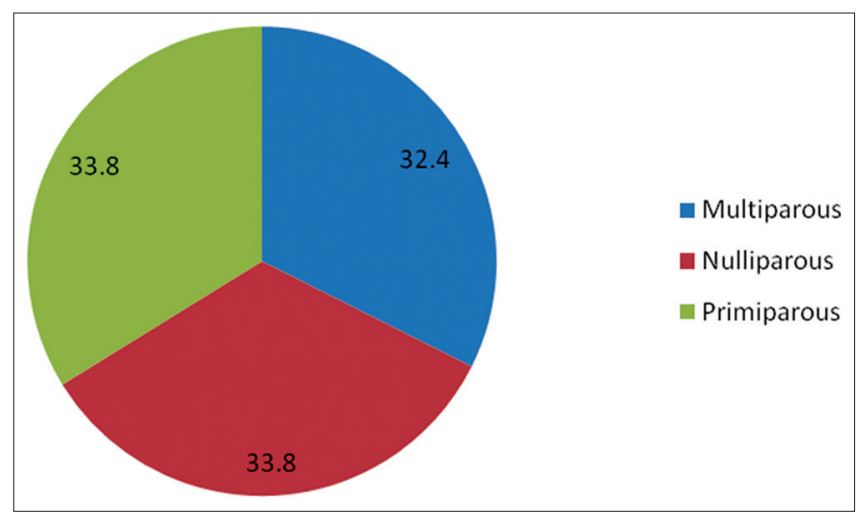

Figure 1: Pie chart showing the proportion of the subjects that used both ITNs and at least two doses of IPT

\begin{tabular}{|c|c|c|}
\hline Factor & Frequency & Percentage \\
\hline \multicolumn{3}{|c|}{ Gestational age } \\
\hline Term & 317 & 96.0 \\
\hline Preterm & 13 & 4.0 \\
\hline \multicolumn{3}{|l|}{ Parity } \\
\hline Para 0 & 115 & 34.9 \\
\hline Para 1 & 100 & 30.3 \\
\hline Para 2 & 70 & 21.2 \\
\hline Para $\geq 3$ & 45 & 13.6 \\
\hline \multicolumn{3}{|c|}{ Maternal HIV status } \\
\hline Positive & 23 & 7.0 \\
\hline Negative & 307 & 93.0 \\
\hline \multicolumn{3}{|c|}{ Maternal malaria parasitaemia } \\
\hline Positive & 100 & 30.3 \\
\hline Negative & 230 & 69.7 \\
\hline \multicolumn{3}{|c|}{ Cord Parasitaemia } \\
\hline Positive & 49 & 14.8 \\
\hline Negative & 281 & 85.2 \\
\hline \multicolumn{3}{|c|}{ Placental malaria } \\
\hline Positive & 60 & 18.2 \\
\hline Negative & 270 & 81.8 \\
\hline \multicolumn{3}{|c|}{ Maternal PCV (\%) } \\
\hline$\geq 33$ & 241 & 73.0 \\
\hline$<33$ & 89 & 27.0 \\
\hline \multicolumn{3}{|c|}{ Haematinics use } \\
\hline Yes & 327 & 99.1 \\
\hline No & 3 & 0.9 \\
\hline \multicolumn{3}{|l|}{ Birth weight } \\
\hline LBW & 17 & 5.2 \\
\hline Normal & 313 & 94.8 \\
\hline \multicolumn{3}{|c|}{ Apgar score at 5 minutes } \\
\hline$\leq 6$ & 11 & 3.3 \\
\hline$\geq 7$ & 319 & 96.7 \\
\hline
\end{tabular}

$($ rho $=0.75 ; \mathrm{p}<0.001)$ and between placental parasitaemia and cord parasitaemia ( $\mathrm{rho}=0.87 ; \mathrm{p}<0.001)$ (Figures 2 and 3).

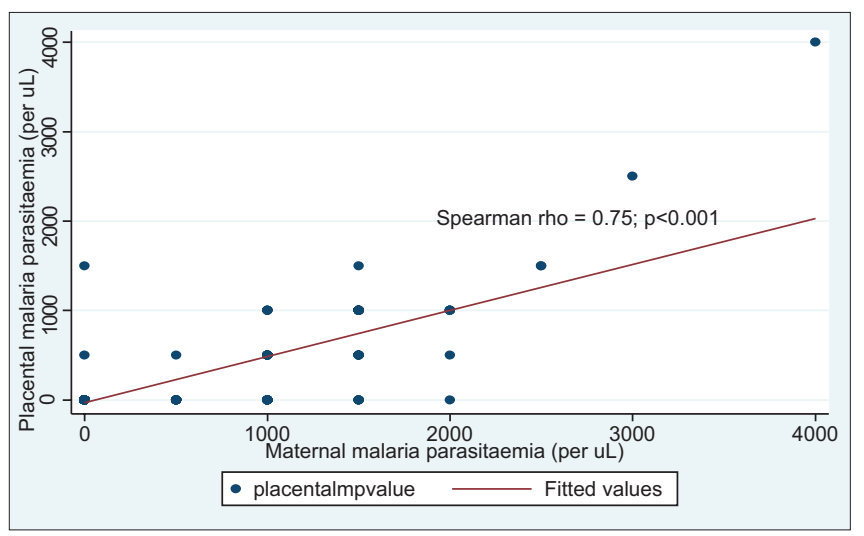

Figure 2: Relationship between placental parasitaemia and maternal parasitaemia

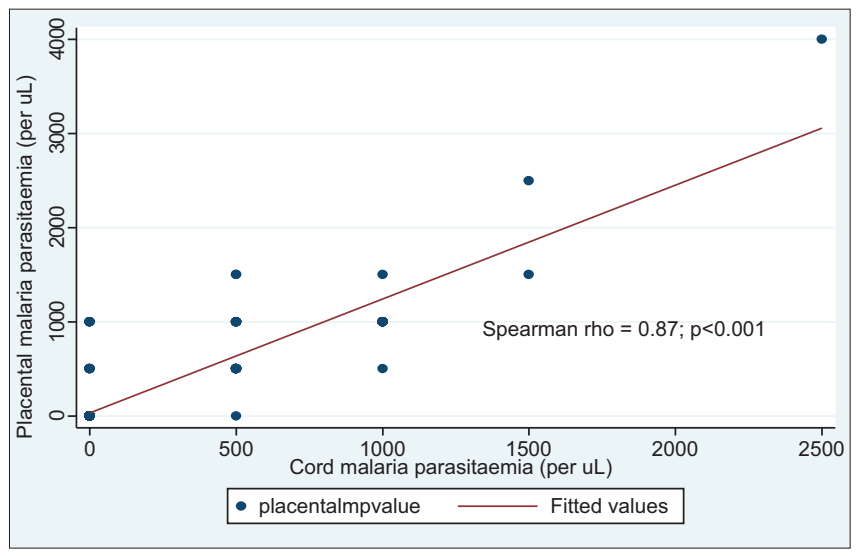

Figure 3: Relationship between placental parasitaemia and cord parasitaemia

\begin{tabular}{lcc} 
Table 3: Use of various malaria control \\
measures by respondents during the antenatal \\
period at UUTH \\
Control measures & Frequency & Percentage \\
\hline ITNs & & \\
Yes & 96 & 29.1 \\
No & 234 & 70.9 \\
Insecticide & & \\
Yes & 290 & 78.8 \\
No & 70 & 21.2 \\
SP-IPT & & \\
Yes & 225 & 68.2 \\
No & 105 & 31.8 \\
$\geq 2$ doses & 113 & 34.2 \\
ITNs + $\geq 2$ doses IPT & 68 & 20.6 \\
Malaria symptoms & & \\
Yes & 218 & 66.1 \\
No & 112 & 33.9 \\
Case treatment of malaria & & \\
Hospital & 216 & 65.5 \\
Chemist & 2 & 0.6 \\
\hline
\end{tabular}

Asian Journal of Medical Sciences | Nov-Dec 2015 | Vol 6 | Issue 6 
Tere was no significant difference between placental parasitaemia and maternal anaemia when controlled for the other confounding variables for maternal anaemia (table4). While that of table 7 is - Also no association was found between placental parasitaemia and preterm delivery after adjusting for the effects of parity, maternal age, use of IPT and ITNs (Table 7).

Placental parasitaemia was also significantly associated with fetal anemia and low birth weight, (Tables 5 and 6).

\section{DISCUSSION}

The prevalence of placental malaria in this study $(18.2 \%)$ is similar to that $(19.9 \%)$ reported by Tako, et al in Cameroon. ${ }^{18}$ Higher rates of $33.2 \%$ and $53.6 \%$ were previously reported by Adebami et $\mathrm{a}^{19}$ and BouyouAkotet et $\mathrm{al}^{20}$ in Ile - Ife, Nigeria and Gabon respectively. The lower prevalence reported in this study may be due to the effective malaria control measures employed in the population, which include sulphadoxine - pyrimethamine

\begin{tabular}{|c|c|c|c|c|}
\hline \multirow[t]{2}{*}{ Variables } & \multicolumn{2}{|c|}{ Univariate analysis } & \multicolumn{2}{|c|}{ Multivariate analysis } \\
\hline & Odds ratio $(95 \% \mathrm{Cl})$ & p value & Odds ratio $(95 \% \mathrm{Cl})$ & $p$ value \\
\hline Placental parasitaemia (per $\mu \mathrm{L})$ & $1.00(0.99-1.00)$ & 0.10 & $1.00(0.99-1.00)$ & 0.15 \\
\hline Maternal age (years) & $1.02(0.95-1.09)$ & 0.66 & $0.98(0.91-1.07)$ & 0.73 \\
\hline \multicolumn{5}{|l|}{ Educational level } \\
\hline Primary & 1 & & 1 & \\
\hline Secondary & $0.67(0.17-2.67)$ & 0.57 & $0.88(0.20-3.78)$ & 0.86 \\
\hline Tertiary & $0.43(0.11-1.68)$ & 0.23 & $0.69(0.16-2.97)$ & 0.61 \\
\hline Parity & $1.28(1.01-1.63)$ & 0.04 & $1.33(1.01-1.77)$ & $0.04^{*}$ \\
\hline Use of ITNs & $0.66(0.31-1.40)$ & 0.28 & $0.62(0.29-1.36)$ & 0.23 \\
\hline HIV positive status & $3.10(1.20-8.02)$ & 0.02 & $3.14(1.16-8.52)$ & $0.03^{*}$ \\
\hline
\end{tabular}

\begin{tabular}{|c|c|c|c|c|}
\hline \multirow[t]{2}{*}{ Variables } & \multicolumn{2}{|c|}{ Univariate analysis } & \multicolumn{2}{|c|}{ Multivariate analysis } \\
\hline & Odds ratio $(95 \% \mathrm{Cl})$ & $p$ value & Odds ratio $(95 \% \mathrm{Cl})$ & $p$ value \\
\hline Placental parasitaemia $($ per $\mu \mathrm{L})$ & $1.02(1.01-1.03)$ & $<0.001$ & $1.02(1.01-1.03)$ & $<0.001^{*}$ \\
\hline Maternal age & $1.03(0.95-1.12)$ & 0.47 & $1.01(0.90-1.12)$ & 0.86 \\
\hline Parity & $1.10(0.83-1.47)$ & 0.51 & $1.15(0.78-1.69)$ & 0.48 \\
\hline Non-use of ITNs & $1.77(0.84-3.75)$ & 0.14 & $3.10(1.27-7.53)$ & $0.01^{*}$ \\
\hline Use of IPT & $0.57(0.27-1.19)$ & 0.13 & $1.94(0.74-5.12)$ & 0.18 \\
\hline Maternal parasitaemia & $1.90(1.01-1.02)$ & $<0.001$ & $1.90(0.67-5.39)$ & 0.23 \\
\hline HIV positive status & $3.81(1.38-10.51)$ & 0.01 & $3.37(1.04-10.89)$ & $0.04^{*}$ \\
\hline
\end{tabular}

\begin{tabular}{|c|c|c|c|c|}
\hline \multirow[t]{2}{*}{ Variables } & \multicolumn{2}{|c|}{ Univariate analysis } & \multicolumn{2}{|c|}{ Multivariate analysis } \\
\hline & Odds ratio $(95 \% \mathrm{Cl})$ & $p$ value & Odds ratio $(95 \% \mathrm{Cl})$ & $p$ value \\
\hline Placental parasitemia & $1.01(0.99-1.01)$ & 0.13 & $1.01(1.001-1.02)$ & $0.04^{*}$ \\
\hline Maternal weight & $0.97(0.93-1.01)$ & 0.13 & $0.98(0.94-1.02)$ & 0.27 \\
\hline \multicolumn{5}{|l|}{ Parity } \\
\hline Nulliparous & 1 & & 1 & \\
\hline Para $\geq 1$ & $1.19(0.82-1.71)$ & 0.36 & $0.70(0.19-2.53)$ & 0.78 \\
\hline Maternal age & $0.84(0.75-0.94)$ & 0.004 & $0.82(0.72-0.93)$ & $0.003^{*}$ \\
\hline Use of IPT & $0.39(0.15-1.05)$ & 0.06 & $0.67(0.22-2.06)$ & 0.49 \\
\hline Use of ITN & $1.01(0.35-2.97)$ & 0.98 & $1.18(0.38-3.63)$ & 0.78 \\
\hline Positive HIV status & $1.85(0.40-8.65)$ & 0.43 & $0.98(0.94-1.02)$ & 0.27 \\
\hline
\end{tabular}

\begin{tabular}{|c|c|c|c|c|}
\hline \multirow[t]{2}{*}{ Variables } & \multicolumn{2}{|c|}{ Univariate analysis } & \multicolumn{2}{|c|}{ Multivariate analysis } \\
\hline & Odds ratio $(95 \% \mathrm{Cl})$ & $p$ value & Odds ratio $(95 \% \mathrm{Cl})$ & $p$ value \\
\hline Placental parasitemia & $1.01(0.99-1.01)$ & 0.14 & $1.01(0.99-1.02)$ & 0.11 \\
\hline Parity & $0.96(0.60-1.53)$ & 0.87 & $0.84(0.73-0.97)$ & $0.02^{*}$ \\
\hline Maternal age & 0.87 (0.76-0.99) & 0.03 & $1.20(0.71-2.01)$ & 0.49 \\
\hline Use of IPT & $0.52(0.17-1.62)$ & 0.27 & $1.20(0.20-2.01)$ & 0.43 \\
\hline Use of ITN & 0.72 (0.19-2.69) & 0.63 & $0.86(0.22-3.31)$ & 0.83 \\
\hline
\end{tabular}


based IPT and ITNs. In this study, 29.1\% of the subjects slept under ITNs while $68.2 \%$ had at least a dose of IPT with $34.2 \%$ having at least 2 doses of IPT. IPT and ITNs use have been reported to be effective in reducing placental malaria. ${ }^{21-23}$ The prevalence of maternal parasitaemia $(30.3 \%)$ and cord parasitaemia $(14.8 \%)$ in this study were similar to those (34.4\% and $18.2 \%$ respectively) reported in Gabon by Bouyou-Akotet, et al. ${ }^{20}$

Several studies have shown that parity influences susceptibility to placental malaria with primigravidae being more susceptible compared to multigravidae. ${ }^{19,24,25}$ In this study, higher parity did not confer any protection and this was consistent with the observations of Bako et al, ${ }^{6}$ SuleOdu et al, ${ }^{8}$ and Ofori et al. ${ }^{24}$ This finding was not surprising as same proportion of women across the various parities (nulliparous, primiparous and multiparous) used ITNs and also had at least 2 doses of IPT.

Maternal malaria parasitaemia usually precedes placental malaria and this was further confirmed by the density of placental parasitaemia which positively correlated with that of maternal malaria parasitaemia. Similar findings have been reported by Bako et $\mathrm{al}^{6}$ and Gilles et $\mathrm{al}^{26}$ in Maiduguri and Burkina Faso respectively. Some of the mothers might have cleared the peripheral parasitaemia at the time of delivery mostly due to the use of IPT and case management of malaria in pregnancy and such mothers had negative malaria parasite even in the presence of placental parasitaemia.

Malaria has adverse effects on pregnancy outcome, causing maternal and fetal anaemia, low birth weight, intrauterine growth restriction, premature delivery, and still births. ${ }^{6-9}$ Various studies have linked placental malaria to maternal anaemia. ${ }^{18,24}$ However, in this study, there was no significant association between placental malaria and maternal anaemia when controlled for the other confounding variables, using the multivariate logistic regression model. This could be attributable to the fact that all the women in the study were booked and received antenatal care that included management of the risk factors for anaemia as well as correction of anaemia. For instance, almost all the women in the study (99.1\%) received haematinics during the antenatal period. High parity and HIV positive status were identified as important risk factors for maternal anaemia in this study. This finding agrees with a study by Al-Farsi, et al where he found that anaemia in pregnancy was three times higher in high parity women compared with low parity pregnancies. ${ }^{27}$ Also, van Eijk et al had found that HIV positivity is an important independent risk factor for anaemia in pregnancy. ${ }^{28}$

Another complication of placental malaria is fetal anaemia which is thought to result from the exposure of the fetus to malaria antigens following the damage of the placental barrier.
The malaria antigens will induce immunologically mediated hemolysis or dyserythropoiesis. ${ }^{29}$ In the logistic regression analysis model for factors associated with fetal anaemia, this study showed a statistically significant relationship between placental malaria and fetal anaemia. Similar finding has been reported by Brabin et al. ${ }^{30}$ Non use of ITNs was found to be significant independent risk factor for fetal anaemia in this study $(\mathrm{P}=0.01)$ This is due to increased risk of placental parasitaemia associated with non-use of ITNs. ${ }^{23}$

Placental malaria was significantly associated with low birth weight in this study. The malaria parasites either directly cause mechanical compromise of placental circulation via widespread trophoblast membrane thickening, increased fibrinoid necrosis and cytotrophoblast prominence or indirectly interfere with placental function and induce pathological lesions. ${ }^{31}$ The finding in this study agrees with those of Bako et al, ${ }^{6}$ Okoko et al, ${ }^{24}$ and Tako et al ${ }^{18}$.

Malaria-infected placentas frequently carry antibodies, cytokines and macrophages which are indicative of an active immune response and these go on to stimulate early labour. ${ }^{32}$ Although some studies have shown an association between increased risk of preterm delivery with placental parasitaemia, ${ }^{33,34}$ the association was not statistically significant in this study. This is similar to the findings of Bako et $\mathrm{al}^{6}$ and Tako et al. ${ }^{18}$

In conclusion, malaria in pregnancy is still a public health problem in Akwa Ibom State. The prevalence of maternal malaria and placental malaria of $30.3 \%$ and $18.2 \%$, respectively, among pregnant women at delivery in UUTH, is alarming and calls for concern as malaria in pregnancy is known to have adverse pregnancy outcomes. The relatively high prevalence in this study despite the various malaria preventive measures that were instituted during the antenatal period, underlines the need for more attention to be focused on easily preventable diseases such as malaria and HIV infection.

Placental malaria is associated with low birth weight, cord parasitaemia, fetal anaemia, and lower mean maternal packed cell volume. HIV sero-positivity and low ITNs usage are risk factors for fetal anaemia. The use of ITNs, IPT and adequate treatment of malaria during pregnancy and prophylaxis against anaemia with haematinics, can significantly protect against placental malaria and its sequelae.

\section{REFERENCES}

1. Uneke CJ. Impact of Plasmodium falciparum malaria on pregnancy and perinatal outcome in sub - Saharan Africa: introduction to placental malaria. Yale J Biol Med 2007; 80(2): 39-50. 
2. Guyatt HL and Snow RW. The epidemiology and burden of plasmodium falciparum-related anemia among pregnant women in sub - Saharan Africa. Am J Trop Med Hyg 2001; 55:100-106.

3. World Health Organization: Rolling Back Malaria. WHO Technical Committee Report. 1999:49-63.

4. Desai M, Kuile FO, Nosten F, McGready R, Asamoah K, Brabin $B$, et al. Epidemiology and burden of malaria in pregnancy. Lancet Infect Dis 2007; 7: $93-104$.

5. Menendez C, D'Alessandro UO and Ter Kuile F. Reducing the burden of malaria in pregnancy by preventive strategies. The Lancet Infectious Diseases 2007; 7(2): 126-135.

6. Bako BG, Audu BM, Geidam AD, Kullima AA, Ashiru GM, Malah MB, et al. Prevalence, risk factors and effects of placental malaria in the UMTH Maiduguri, north-east Nigeria: crosssectional study. Journal of Obstetrics and Gynaecology 2009; 29(4): 307-310.

7. Kalanda BF, Verhoeff FH, Chimsuku L, Harper G and Brabin BJ. Adverse birth outcomes in a malarious area. Epidemiol Infect 2006; 134: 659-666.

8. Sule-Odu AO, Ogunledun $A$ and Olatunji AO. Impact of asymptomatic maternal malaria parasitaemia at parturition on perinatal outcome. Journal of Obstetrics and Gynaecology 2002; 22(1): 25-28.

9. Mokuolu OA, Falade CO, Orogade AA, Okafor HU, Adedoyin TO, Oguonu TA, et al. Malaria at parturition in Nigeria: Current Status and Delivery Outcome. Infectious Diseases in Obstetrics and Gynaecology 2009; 1-7.

10. Ekweozo C. Malaria. In: Iheanyi Okpala, Cage Johnson (eds). Synopsis of Haematology 2010: $17-45$.

11. Sowunmi A. Malaria during pregnancy. In: Okonofua F, Odunsi K (eds). Contemporary Obstetrics and Gynaecology for Developing Countries. Benin City, Nigeria. Women's Health and Action Research Centre 2003; 502-514.

12. Shulman CE. Malaria in pregnancy: relevance to safe motherhood programme. Ann Trop Med Parasitology 1999; 93: 1-3.

13. Andrews KT and Lanzer M. Maternal Malaria: Plasmodium falciparum sequestration in the placenta. Parasitol Research 2002; 88(8): 715-723.

14. World Health Organization. A Strategic framework for malaria prevention and control during pregnancy in the African Region. Geneva, Switzerland 2004; 6-8.

15. Ezeoke ACJ, Ibanga NJ and Braide El. Congenital malaria at University of Calabar Teaching Hospital, with reference to hemoglobin and immunoglobulin. Central Africa J Med 1985; 31: 241-247.

16. Sowunmi A, Aboweyere AEJ, Akindele JA, llesanmi AO, Falade $\mathrm{CO}$ and Oduola AMJ. Comparison of the incision and aspiration methods for the diagnosis of placental malaria infection. J Obstet Gynaecol 1996; 16: 316-320.

17. Greenwood BM and Armstrong JRM. Comparison of two simple methods for determining malaria parasite density. Trans $\mathrm{R}$ Soc Trop Med Hyg 1991; 85: 186- 188.

18. Tako EA, Zhou A, Lohoue J, Leke R, Taylor DW, Leke RF, et al. Risk factors for placental malaria and its effects on pregnancy outcome in Yaounde, Cameroun. Am J Trop Med Hyg 2005; 72: 236-242.

19. Adebami OJ, Owa JA, Oyedeji GA, Oyelami OA and OmoniyiEsan GO. Association between placental and cord blood malaria infection and fetal malnutrition in an area of malaria holoendemicity. Am J Trop Hyg 2007; 77(2); 209-213.

20. Bouyou-Akotet MK, Nzenze-Afene S, Ngoungou EB, Kendjo E, Owono-Medang M, Lekana-Douki J, et al. Burden of malaria during pregnancy at the time of IPT/SP implementation in Gabon. Am J Trop Med Hyg 2010; 82(2): 202-209.

21. Aziken ME, Akubuo KK and Gharoro EP. Efficacy of intermittent preventive treatment with sulfadoxine-pyrimethamine on placental parasitaemia in pregnant women in mid-west Nigeria. Int. J. Gynecol Obstet 2010: doi: 10.1016/j. ijgo 2010.07.027.

22. Falade CO, Bidemi OY, Fadero FF, Mokuolu OA, Hamer DH and Salako LA. Intermittent preventive treatment with sulphadoxinepyrimethamine is effective in preventing maternal and placental malaria in Ibadan, south-western Nigeria. Malaria Journal 2007. Available at http://www.malariajournal.com/contents/6/1/88.

23. Oduro AR, Fryauff DJ, Koram KA, Rogers WO, Anto F, Atuguba F, et al. Sulphadoxine-pyrimethamine-based intermittent preventive treatment, bed net use, and antenatal care during pregnancy: demographic trends and impact on the health of newborns in the Kassena District, north- eastern Ghana. Am J Trop Med Hyg 83(1), 2010: 79-89.

24. Ofori MF, Ansah E, Agyepong I, Ofori-Adjei D, Hviid L and Akanmori BD. Pregnancy-associated malaria in a rural community of Ghana. Ghana Medical Journal 2009; 43(1): 13-18.

25. O'Neil-Dunne I, Achur RN, Agbor-Enoch ST, Valiyaveettil M, Naik RS, et al. Gravidity-dependent production of antibodies that inhibit binding of plasmodium falciparum-infected erythrocytes to placental chondroitin sulphate proteoglycan during pregnancy. Infect Immun 2001; 69(12): 7487-7492.

26. Gilles C, Jean-Yves M, Drissa B and Michel C. Is malarial placental infection related to peripheral infection at any time of pregnancy? Am J. Trop. Hyg 2005; 73(6): 1112-1118.

27. Al-Farsi YM, Brooks DR, Werler MM, Cabral HJ, Al-Shafei MA, et al. Effects of high parity on occurrence of anemia in pregnancy: a cohort study. BMC Pregnancy and Childbirth 2011; 11: 1-7.

28. Van Eijk AM, Ayisi JG, Kuile FO, Misore AO, Otieno JA, et al. Human immunodeficiency virus seropositivity and malaria as risk factors for third-trimester anemia in asymptomatic pregnant women in Western Kenya. Am J Trop Med Hyg 2001; 65(5): 623-630.

29. Brabin B. Fetal anemia in malarious areas: its causes and significance. Ann Trop Pediatr 1992; 12: 303-310.

30. Brabin BJ, Kalande BF,Verhoeff FH, Chimsuku LH and Broadhead RL. Risk factors for fetal anemia in a malarious area of Malawi. Ann Trop Pediatr 2004; 24: 311-321.

31. Uneke CJ. Impact of placental plasmodium falciparum malaria on pregnancy and perinatal outcome in sub-aharan Africa II: effects of placental malaria on perinatal outcome; malaria and HIV. Yale Journal of Biololgy and Medicine. 2007 (80): 95-103.

32. Guyatt $\mathrm{HL}$ and Snow RW. Impact of malarial during pregnancy on low birth weight in Sub-Saharan Africa. Clin Microbiol Rev 2004; 17: 760-769.

33. Okoko BJ, Ota MO, Yamuah LK, Idiong D, Mkpanam SN, Avieka A, et al. Influence of placental malaria infection on fetal outcome in the Gambia: twenty years after lan McGregor. J Health Popul Nutr 2002; 20(1): 4-11.

34. Menendez C, Ordi J, Ismail MR, Ventura PJ, Aponte JJ, et al. The impact of placental malaria on gestational age and birth weight. J Infect Dis 2000; 181: 1740-1745.

\footnotetext{
Authors Contribution:

Dr G lbanga - Initiated and designed the study, interpreted the data and drafted the manuscript.

Source of Support: Nil, Conflict of Interest: None declared.

Drs' A. Abasiattai, E. Bassey and O. Olatunbosun - Substantially contributed to the design of the manuscript and interpretation of data and critically reviewed

it for intellectual content; Dr U Ekrikpo - Analyzed the data and also reviewed the manuscript. All the authors approved the final version to be published. 